\title{
ĐÁNH GIÁ ĐẶC ĐIỂM LÂM SÀNG, CẬN LÂM SÀNG VÀ TỶ LỆ GAN NHIỄM MỠ TRÊN BÊNH NHÂN CÓ HỘI CHÚNG CHUYỂN HÓA BẦNG MÁY FIBROSCAN TOUCH TẠI BỆNH VIỆN 19-8, BỘ CÔNG AN Nguyễn Thị Hoa \\ Bệnh viện 19-8, Bộ Công An
}

DOI: $10.47122 /$ vjde.2020.45.10

\section{TÓM TÁ́T}

Muc tiêu: Đánh giá được lâm sàng, cận lâm sàng của bệnh nhân có hội chứng chuyển hóa và xác định được tỷ lệ các mức độ gan nhiễm mỡ độ I, II, III bằng máy Fibroscan Touch. Đối tựng và phương pháp nghiên cứu: Mô tả cắt ngang, khám sàng lọc 100 bệnh nhân có hội chứng chuyển hóa (theo tiêu chuẩn AHA / NHLBI + IDF (2009)) từ 600 bệnh nhân đến khám tại khoa điều trị Cao cấp, Bệnh viện 19-8, bộ Công An. Kết quả: 100 đối tượng nghiên cứu có hội chứng chuyển hóa được đo độ nhiễm mỡ gan bằng máy Fibroscan Touch 502, kết quả cho thấy $92 \%$ số bệnh nhân trong nghiên cứu có gan nhiễm mõ̃ ở các mức độ khác nhau.

Tù khóa: Hội chứng chuyển hóa, gan nhiễm mõ không do rượu

\section{ABSTRACT \\ Evaluating clinical and subclinical characteristics and fatty liver rate of patients with metabolic syndrome by FibroScan \\ Touch at the Advanced Treatment Department of 19-8 Hospital, Ministry of Public Security \\ Nguyen Thi Hoa \\ 19/8 Hospital, Ministry of Public Security}

Objectives: To evaluate the clinical, subclinical of the patient with metabolic syndrome and determine the rate of fatty liver degree level I, II, III by using Fibroscan Touch. Subjects and research methods: Cross-sectional description, screening of 100 patients with metabolic syndrome (according to AHA / NHLBI + IDF standards (2009)) from 600 patients checked at the hospital 19-8 of Ministry of Public Security. Results: 100 patients with metabolic syndrome were measured with fatty liver with Fibroscan Touch 502, results showed that $92 \%$ of the patients in the study had fatty liver at different levels.

Keywords: Metabolic syndrome $=$ MetS: Non - alcocholic fatty liver desease $=$ NAFLD

Chịu trách nhiệm chính: Phạm Tuấn Dương

Ngày nhận bài: 5/1/2021

Ngày phản biện khoa học: 11/1/2021

Ngày duyệt bài: 4/3/2021

Email: duongbs198@gmail.com

Điên thoại: 0982017105

\section{1. ĐẶT VẤN ĐỀ}

Có nhiều định nghĩa về hội chứng chuyển hóa nhưng định nghĩa của Liên đoàn Đái tháo đường Quốc tế (IDF) về hội chứng chuyển hóa đã được toàn cầu đồng thuận: là một nhóm các yếu tố nguy cơ đau tim nguy hiểm nhất bao gồm đái tháo đường và tiền đái tháo đường, béo bụng, cholesterol cao và huyết áp cao. Định nghĩa này cung cấp cho các bác sĩ những công cụ để xác định nhanh những người có nguy cơ mắc bệnh.

Tỷ lệ mắc Mets ở các nước phương Tây là 28,5-38,5\%, ở Hoa Kỳ theo các tiêu chuẩn khác nhau tỷ lệ này dao động 34-40\% [1], Châu Á là 20-25\%, trong đó ở Trung Quốc là $26,1 \%$ [2].

Gan nhiễm mỡ là tình trạng tích tụ quá nhiều mỡ ở gan $>5 \%$ trọng lượng gan (chủ yếu là Triglycerid). Gan nhiễm mỡ không do rượu - NAFLD là tình trạng gan nhiễm mỡ mà căn nguyên không do rượu. Theo thời gian NAFLD sẽ tiến triển thành viêm gan nhiễm mỡ (NASH), dần trở thành xơ gan và ung thư gan nguyên phát (HCC) [3].

Theo một nghiên cứu của Trung Quốc, cho thấy có mối liên quan giữa Mets và NAFLD, tỷ lệ mắc NAFLD ở các đối tượng Mets là rất cao, dao động từ $56 \%$ đến $70 \%$ [4], cao hơn nhiều so với tỷ lệ NAFLD trong dân số nói chung. Vì vậy chúng tôi tiến hàng nghiên cứu 
“Đánh giá đặc điểm lâm sàng, cận lâm sàng và tỷ lệ gan nhiếm mõ trên bệnh nhân có họi chưng chuyển hóa bằng máy Fibroscan Touch tại Bệnh viện 19-8".

\section{2. ĐỐI TƯợNG VÀ PHƯƠNG PHÁP NGHIÊN CÚU}

\section{1. Đối tượng nghiên cứu}

\subsection{1. Địa điểm và thời gian nghiên cứu}

Địa điểm: Khoa điều trị Cao Cấp, Bệnh viện 19-8 Bộ Công An

Thời gian: từ 1-2020 đến tháng 12-2020

\subsubsection{Tiêu chuẩn chọn bệnh nhân}

Bệnh nhân có hội chứng chuyển hóa theo tiêu chuẩn AHA / NHLBI + IDF (2009): bệnh nhân có bất kỳ $3 / 5$ thành phần dưới [5].

1. Tăng vòng bụng: $N a m \geq 90 \mathrm{~cm}$, nữ $\geq 80 \mathrm{~cm}$

2. Triglycerid $\geq 150 \mathrm{mg} / \mathrm{dl}(\geq 1.7 \mathrm{mmol} / \mathrm{l})$ hoặc đang điều trị.

3.Và hoặc giảm HDL-C:Nam $<40 \mathrm{mg} / \mathrm{dl}(<$ $1.04 \mathrm{mmol} / \mathrm{l}) ; \quad \mathrm{Nu \tilde {u }}<50 \mathrm{mg} / \mathrm{dl}(<1.3 \mathrm{mmol} / \mathrm{l})$ hoặc đang điều trị.

4. Huyết áp: $\geq 130 / 85 \mathrm{mmHg}$ hoặc tăng huyết áp đang điều trị.

5. Glucose máu $>100 \mathrm{mg} / \mathrm{dl}(>5.6 \mathrm{mmol} / \mathrm{l})$ (bao gồm cả đái tháo đường)

\subsubsection{Tiêu chuẩn loại trù̀}

- Bệnh nhân có thai; Bệnh nhân nghiện rượu

- Bệnh nhân mắc bệnh viêm gan virus mạn: viêm gan $\mathrm{B}$, viêm gan $\mathrm{C}$...

- Bệnh nhân mắc các bệnh nội tiết như hội chứng Cushing, dùng corticoid kéo dài, dùng thuốc tránh thai kéo dài...

- Bệnh nhân có dịch ổ bụng

- Tổn thương gan cấp: áp xe gan, ứ mật, suy tim phải - ứ huyết ở gan

- Bệnh nhân có cấy ghép máy tạo nhịp tim, máy khử rung tim.

- Bệnh nhân không có khả năng nằm thẳng

\subsection{Phương pháp nghiên cứu}

2.2.1. Thiết kế nghiên cứu: Nghiên cứu mô tả cắt ngang

\subsubsection{Cõ̃ mẫu và phương pháp chọn mẫu:} Khám sàng lọc chọn ra cỡ mẫu thích hợp theo tiêu chuẩn chẩn đoán hội chứng chuyển hóa.

\subsubsection{Phương tiện nghiên cứu}

- Khám lâm sàng sàng lọc: Bệnh nhân được hỏi tiền sử bệnh, đo vòng bụng, đo chỉ số khối cơ thể $(\mathrm{BMI}=$ Cân nặng $(\mathrm{kg}) /[$ chiều cao $(\mathrm{m})] 2$, đo huyết áp

Theo tồ chức Y tế Thế giới (World Health Organization: WHO) áp dụng cho khu vực Châu Á - Thái Bình Dương gọi là thừa cân và béo phì khi chỉ số BMI $\geq 23 \mathrm{~kg} / \mathrm{m} 2$ [6].

- Xét nghiệm máu bằng máy Beckman Coulter Au 680 và Arkray

- Đo độ đàn hồi nhu mô gan bằng máy Fibroscan Touch 502, chỉ số gan nhiễm mỡ CAP (Controlled Attenuation Parameter) - đơn vị $\mathrm{dB} / \mathrm{m}$

2.2.4. Xử lí số liệu: Bằng phần mềm SPSS 20.0 có độ tin cậy $>95 \%$.

\section{KẾT QUẢ NGHIÊN CỨU VÀ BÀN LUẬN}

Sau một thời gian thực hiện nghiên cứu, chúng tôi thu được những kết quả sau:

\section{1. Đặc điểm lâm sàng và cận lâm sàng}

Bảng 1. Đặc điểm lâm sàng $(\mathrm{n}=100)$

\begin{tabular}{|c|c|c|c|c|}
\hline \multicolumn{3}{|c|}{ Đặc điểm } & $\mathbf{N}$ & $\%$ \\
\hline \multirow{6}{*}{ Tuổi } & \multicolumn{2}{|c|}{$<30$} & 1 & 1 \\
\hline & \multicolumn{2}{|c|}{$30-39$} & 0 & 0 \\
\hline & \multicolumn{2}{|c|}{$40-49$} & 4 & 4 \\
\hline & \multicolumn{2}{|c|}{$50-59$} & 40 & 40 \\
\hline & \multicolumn{2}{|c|}{$60-69$} & 42 & 42 \\
\hline & \multicolumn{2}{|c|}{$>70$} & 13 & 13 \\
\hline \multirow{4}{*}{ Chỉ số vòng bụng } & \multirow{2}{*}{$\operatorname{Nam}(n=72)$} & $\mathrm{Nam} \geq 90$ & 61 & 84,7 \\
\hline & & $\mathrm{Nam}<90$ & 11 & 15,3 \\
\hline & \multirow{2}{*}{ Nữ $(n=28)$} & Nữ $\geq 80$ & 26 & 92,9 \\
\hline & & Nữ $<80$ & 2 & 7,1 \\
\hline
\end{tabular}




\begin{tabular}{|c|c|c|c|}
\hline \multirow{4}{*}{ Chỉ số BMI } & $<18:$ gầy & 0 & 0 \\
\cline { 2 - 4 } & $18,5-22,9:$ bình thường & 16 & 16 \\
\cline { 2 - 4 } & $23-24,9:$ thừa cân & 25 & 25 \\
\cline { 2 - 4 } & $25-29,9:$ béo phì độ I & 47 & 47 \\
\cline { 2 - 4 } & $30-35:$ béo phì độ II & 11 & 11 \\
\hline
\end{tabular}

Tuổi trung bình $(\bar{X} \pm S D)$

$60.40 \pm 7.93$

Nhóm tuối gặp nhiều nhất là từ 50 đến 69 tuổi (chiếm 40 và $42 \%$ ) tỷ lệ này phù hợp với nghiên cứu của Nguyễn Thị Trung Thu, Trần Quang Bình (tỷ lệ nhóm tuổi 50-59 là 59,3\%) [7].

Với chỉ số khối cơ thể $\mathrm{BMI}$, hai nhóm có chỉ số $\mathrm{BMI}$ cao là nhóm thừa cân và béo phì độ $\mathrm{I}$ ( $25 \%$ và $47 \%)$, tỷ lệ này phù hợp với nghiên cứu của Phạm Công Chánh $(31 \%$ và $57.4 \%)$ [8]. Béo phì và thừa cân là một trong các yếu tố làm tăng sự đề kháng insulin, làm tăng nguy cơ mắc bệnh chuyển hóa và tim mạch.

Béo bụng trung tâm chiếm đa số trong nghiên cứu với tỷ lệ nam chiếm $84.7 \%$ và nữ chiếm $92.9 \%$, tỷ lệ này tương đồng với nghiên cứu của Phạm Công Chánh $(77.9 \%$ và $96.1 \%)$ [8].

Bảng 2. Đặc điểm rối loạn lipid máu

\begin{tabular}{|l|c|c|}
\hline \multicolumn{1}{|c|}{ Tình trạng rối loạn lipid máu } & $\mathbf{N}$ & $\mathbf{\%}$ \\
\hline Tăng Triglycerid đơn thuần & 36 & 36 \\
\hline Giảm HDL - chol & 7 & 7 \\
\hline Hỗn hợp & 57 & 57 \\
\hline Không mắc & 0 & 0 \\
\hline Tổng & 100 & 100 \\
\hline
\end{tabular}

Tình trạng rối loạn lipid máu hỗn hợp chiếm tỷ lệ cao nhất trong nghiên cứu

Bảng 3. Mức độ biến đổi men gan

\begin{tabular}{|l|c|c|}
\hline \multicolumn{1}{|c|}{ Mức độ } & $\mathbf{N}$ & $\mathbf{\%}$ \\
\hline Bình thường & 72 & 72 \\
\hline Tăng < 2 lần & 22 & 22 \\
\hline Tăng 2-3 lần & 1 & 1 \\
\hline Tăng > 3 lần & 5 & 5 \\
\hline
\end{tabular}

Men gan chủ yếu bình thường, điều này cũng phù hợp với tình trạng nghèo nàn triệu chứng gan nhiễm mỡ trên lâm sàng.

\subsection{Tỷ lệ gan nhiễm mõ̃, xơ hóa gan và mối liên quan}

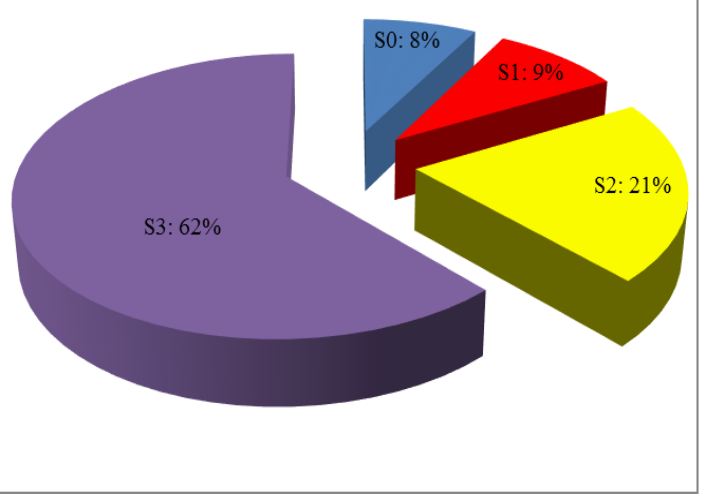

Biểu đồ 1. Tỷ lệ gan nhiễm mỡ trong nghiên cứu

Chỉ CAP: $(\bar{X} \pm S D) 299,1 \pm 4,8$ 
Độ gan nhiễm mỡ $\mathrm{S} 3$ chiếm tỷ lệ lớn $(62 \%)$ trong nhóm đối tượng nghiên và chỉ có $8 \%$ là không mắc gan nhiễm mỡ. Chỉ số CAP thấp nhất là $153 \mathrm{~dB} / \mathrm{m}$ và cao nhất là $387 \mathrm{~dB} / \mathrm{m}$.

Trong nghiên cứu có $92 \%$ mắc gan nhiễm mỡ ở các mức độ khác nhau, tỷ lệ này cao hơn trong nghiên cứu của Shao Hua CHEN (62.78\%) [4]. Có sự khác biệt về tỷ lệ này là do sử dụng 2 phương pháp chẩn đoán NAFLD khác nhau.

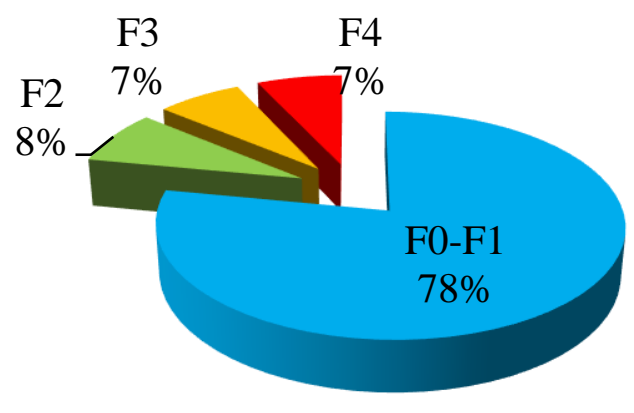

Biểu đồ 2. Độ cứng của gan (độ xơ hóa gan)

Có $14 \%$ bệnh nhân có xơ hóa gan tiến triển $(\mathrm{F}>\mathrm{F} 3)$, tương tự nghiên cứu của Kwok $\mathrm{R}(17,7 \%)$ [9].

Tỷ lệ xơ hóa gan đáng kể F2, xơ hóa gan tiến triển $\mathrm{F} 3$ và xơ gan $\mathrm{F} 4$ trong nghiên cứu của chúng tôi là $8 \%-7 \%-7 \%$, có khác so với nghiên cứu của Trần Thị Khánh Tường $(13 \%-5.9 \%-3.6 \%)$, sự khác này là do quần thể nghiên cứu của chúng tôi có tiêu chuẩn chẩn đoán rộng hơn [10].

Bảng 4. Tương quan NAFLD và chỉ số BMI

\begin{tabular}{|c|c|c|c|c|c|c|c|c|c|}
\hline & \multicolumn{4}{|c|}{ Độ gan nhiễm mõ̃ } & \multirow{2}{*}{ Total } & \multirow{2}{*}{$\mathbf{p}$} & \multirow{2}{*}{$\mathbf{r}$} \\
\hline & & & S0 & $\mathrm{S} 1$ & $\mathrm{~S} 2$ & $\mathrm{~S} 3$ & & & \\
\hline \multirow{10}{*}{$\begin{array}{c}\text { Phân } \\
\text { độ } \\
\text { BMI }\end{array}$} & \multirow{2}{*}{$\begin{array}{l}\text { Bình } \\
\text { thường }\end{array}$} & $\mathrm{N}$ & 3 & 4 & 3 & 6 & 16 & \multirow{12}{*}{0,015} & \multirow{12}{*}{0,291} \\
\hline & & $\%$ & $18,8 \%$ & $25,0 \%$ & $18,8 \%$ & $37,5 \%$ & $100,0 \%$ & & \\
\hline & \multirow{2}{*}{ Thừa cân } & $\mathrm{N}$ & 1 & 1 & 7 & 16 & 25 & & \\
\hline & & $\%$ & $4,0 \%$ & $4,0 \%$ & $28,0 \%$ & $64,0 \%$ & $100,0 \%$ & & \\
\hline & \multirow{2}{*}{$\begin{array}{l}\text { Béo phì } \\
\text { độ I }\end{array}$} & $\mathrm{N}$ & 4 & 4 & 9 & 30 & 47 & & \\
\hline & & $\%$ & $8,5 \%$ & $8,5 \%$ & $19,1 \%$ & $63,8 \%$ & $100,0 \%$ & & \\
\hline & \multirow{2}{*}{$\begin{array}{l}\text { Béo phì } \\
\text { độ II }\end{array}$} & $\mathrm{N}$ & 0 & 0 & 2 & 9 & 11 & & \\
\hline & & $\%$ & $0,0 \%$ & $0,0 \%$ & $18,2 \%$ & $81,8 \%$ & $100,0 \%$ & & \\
\hline & \multirow{2}{*}{$\begin{array}{l}\text { Béo phì } \\
\text { độ III }\end{array}$} & $\mathrm{N}$ & 0 & 0 & 0 & 1 & 1 & & \\
\hline & & $\%$ & $0,0 \%$ & $0,0 \%$ & $0,0 \%$ & $100,0 \%$ & $100,0 \%$ & & \\
\hline \multirow{2}{*}{\multicolumn{2}{|c|}{ Tổng }} & $\mathrm{N}$ & 8 & 9 & 21 & 62 & 100 & & \\
\hline & & $\%$ & $8,0 \%$ & $9,0 \%$ & $21,0 \%$ & $62,0 \%$ & $100,0 \%$ & & \\
\hline
\end{tabular}

Trong nghiên cứu của chúng tôi, mức độ gan nhiễm mõ̃ có mối quan hệ tuyến tính với độ béo phì. Độ béo phì càng cao, gan nhiễm mỡ càng nhiều. Mức độ tuyến tính này tương đương trong nghiên cứu của Phạm Thúy Hường và Huỳnh Công Minh [11]; [12]. 


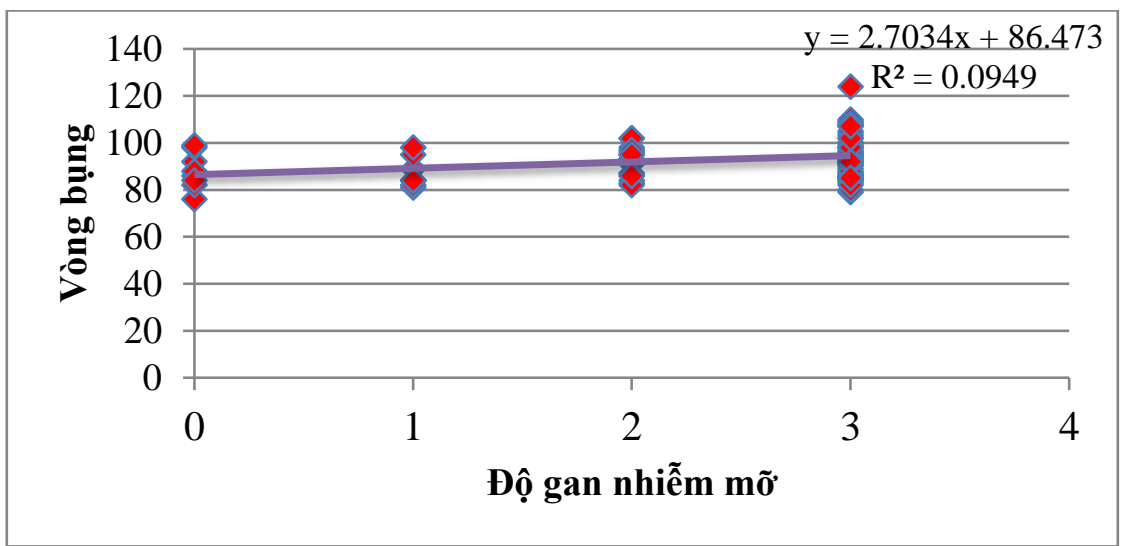

Biểu đồ 3. Tương quan NAFLD và chỉ số vòng bụng

Tương quan giữa gan nhiễm mỡ và vòng bụng, $\mathrm{r}=0,31 ; \mathrm{p}=0,003 ; \mathrm{n}=100$.

Nhận xét: Qua biểu đồ ta thấy mối tương quan thuận giữa vòng bụng và NAFLD, vòng bụng tăng độ nhiễm mỡ tăng. Mối tương quan thuận này cũng gặp trong nghiên cứu của Huỳnh Công Minh [12].

\section{KẾT LUẬN}

- Nhóm tuổi gặp nhiều nhất trong nghiên cứu 50-69 tuổi (82\%).

- Trong các nhóm phân loại BMI, nhóm bệnh nhân có thừa cân và béo phì độ $\mathrm{I}$ chiếm số nhiều trong nghiên cứu ( $25 \%$ và $47 \%)$.

- Tình trạng rối loạn chuyển hóa lipid hỗn hợp chiếm tỷ lệ cao nhất trong nhóm rối loạn chuyển hóa lipid.

- Bệnh nhân trong nghiên cứu không có tăng men gan chiếm tỷ lệ rất cao trong nghiên cứu.

- Tổng tỷ lệ NAFLD trong nhóm nghiên cứu cao $(92 \%)$, trong đó NAFLD độ S3 chiếm cao nhất $62 \%$.

- Chỉ số Vòng bụng và BMI có mối tương quan thuận với độ nhiễm mỡ gan.

- Có một tỷ lệ đáng kể (14\%) bệnh nhân xơ hóa gan tiến triển và xơ gan $\mathrm{F} 3-\mathrm{F} 4$, mặc dù không có biểu hiện lâm sàng.

\section{TÀI LIÊUU THAM KHẢO}

1. Metabolic Syndrome Knowledge among Adults with Cardiometabolic Risk Factors: A Cross-Sectional Study. International Journal of Environmental Research and Public Health - Open Access Journal, January 2019

2. Li R., Li W.C., Lun Z.J., Zhang H.P., Sun
Z., Kanu J.S., Qiu S., Cheng Y., Liu Y.W "Prevalence of metabolic syndrome in mainland China: A meta-analysis of published studies" BMC Public Health. 2016;16:296. doi: 10.1186/s12889-0162870-y

3. Chalasani N, Younossi Z, Lavine JE, et al. "The diagnosis and management of nonalcoholic fatty liver disease: practice guideline by the American Gastroenterological Association, American Association for the Study of Liver Diseases, and American College of Gastroenterology"

Gastroenterology. 2012;142:1592-1609

4. Shao Hua CHEN, Fan HE, Hua Li ZHOU, Hong Ru WU, Chen XIA You Ming LI "Relationship between nonalcoholic fatty liver disease and metabolic syndrome". https://doi.org/10.1111/j.17512980.2011.00487.x

5. http://www.idf.org/metabolic_syndrome, website of the International Diabetes Federation.

6. International Obesity Task Force, World Health Prganization - Western Pacific Region (2000), "The Asia-Pacific perspective: redefining obesity and its 
treatment".

7. Nguyễn Thị Trung Thu, Trần Quang Bình "Hội chứng chuyển hóa và yếu tố nguy cơ ở người trung niên bị tiền đái tháo đường”, Tạp chí Khoa học ĐHQGHN: Khoa học Tự nhiên và Công nghệ, Tập 33, Số 1 (2017) 67-73

8. Phạm Công Chánh "Nghiên cứu đặc điểm lâm sàng, cận lâm sàng ở bệnh nhân gan nhiễm mỡ không do rượu tại trung tâm y khoa Medic, Thành phố Hồ Chí Minh" tạp trí hội gan mật, vasld

9. Kwok R, Choi KC, Wong GL, et al. Screening diabetic patients for nonalcoholic fatty liver disease with controlled attenuation parameter and liver stiffness measurements: a prospective cohort study. Gut 2015 Apr 14; (Epub ahead of print).

10. Tran Thi Khanh Tuong, Dang Khoa Tran, Pham Quang Thien Phu, Tong Nguyen
Diem Hong, Thien Chu Dinh, Dinh Toi Chu "Non-Alcoholic Fatty Liver Disease in Patients with Type 2 Diabetes: Evaluation of Hepatic Fibrosis and Steatosis Using Fibroscan" Diagnostics 2020, 10(3),59; https://doi.or g/10.3390/diagnostics10030159

11. Phạm Thúy Hường "Nghiên cứu đặc điểm hội chứng chuyển hóa theo các tiêu chuẩn khác nhau ở người tiền đái tháo đường và kết quả can thiệp cộng đồng". Luận án Tiến sỹ Y học. Học viện Quân Y 2018

12. Huỳnh Công Minh, Văn Thị Thanh Vân, Lê Viết Khâm, Huỳnh Thế Thiện Giác, Huỳnh Thị Sáu, Nguyễn Thị Thanh Thúy "Nghiên cứu hội chứng chuyển hóa trên bệnh nhân gan nhiễm mỡ đến khám tại phòng Bảo vệ sức khỏe cán bộ tỉnh Thừa Thiên Huế", Tạp chí điện quang Việt Nam. Số 29 - 1/2018 